- This paper examines dentists' knowledge, attitude and practices to assess factors affecting willingness to treat HIV/AIDs patients and those with other blood borne viruses.

- Age and type of dental practice are significant factors associated with treatment practices.

- Further qualitative research is required.

\title{
An investigation of dentists' knowledge, attitudes and practices towards HIV+ and patients with other blood-borne viruses in South Cheshire, UK
}

\author{
M. L. Crossley ${ }^{1}$
}

\begin{abstract}
This paper derives from research conducted in the North West of England which was funded by the South Cheshire Health Authority. The research was funded because anecdotal evidence within a charity HIV/ AIDS organisation in the region suggested that some HIV positive individuals had been experiencing difficulties accessing NHS dental care. Following previous studies, this paper therefore examines dentists' knowledge, attitudes and practices in order to assess which factors may be influential in affecting dentists' willingness to treat patients with HIV/AIDS and other blood-borne viruses. The study population consisted of all 330 dentists working within the South Cheshire region whose addresses were obtained from the Local Health Authority. A response rate of $46 \%$ was obtained and the results were analysed using basic descriptive statistics and the chi-squared $\left(\chi^{2}\right)$ test. The results of this study suggest that age and type of dental practice are significant factors associated with treatment practices, attitudes and sense of ethical responsibility amongst dentists in the South Cheshire region. Consistent with previous studies, this could be interpreted as due to the impact of educational programmes. Further qualitative research is recommended in order to address these issues in more depth.
\end{abstract}

Previous research has suggested that dental care providers have an ethical and legal obligation to treat HIV infected patients. ${ }^{1}$ In Canada and the US refusal to treat patients who have infectious diseases such as HIV or hepatitis viruses can result in charges of discrimination to human rights organisations. It is in response to these concerns that dental associations have issued recommendations indicating that dentists are obligated to provide care for patients with infectious diseases. Despite these recommendations, however, it has been suggested that many dentists remain

1*Professor, Liverpool John Moore's University, Faculty of Health and Applied Social Studies, Josephine Butler House, Myrtle Street, Liverpool L1 7DN

${ }^{*}$ Correspondence to: Prof. Michele L. Crossley

Email: M.Crossley@livjm.ac.uk

\section{Refereed Paper}

doi:10.1038/sj.bdj.4811382

Received 15.01.03; Accepted 12.08.03

$\odot$ British Dental Journal 2004; 196: 749-754 reluctant to treat patients with HIV/AIDS and other groups at high risk for bloodborne pathogens. ${ }^{2}$ Previous studies in both the UK ${ }^{3}$ and $U^{4,5}$ have examined dentists' knowledge, attitudes and behaviours in order to assess which factors may be influential in affecting dentists' willingness to treat HIV/AIDS patients. It has been suggested, for instance, that dentists' attitudes and behaviours towards HIV/AIDS patients may be a reflection of their knowledge of HIV/AIDS. ${ }^{1,2}$

This paper derives from research conducted in the North West of England and funded by South Cheshire Health Authority. The Health Authority felt there was a need for this research because anecdotal evidence within an influential charity HIV/ AIDS organisation in the region suggested that some HIV positive individuals had been experiencing difficulties accessing NHS dental care. The research set out to examine both patient and dentists' per- spectives on this issue, and this paper reports the arm of the research concerned with the latter. In particular, it reports on the investigation of NHS dentists' knowledge, attitudes and practices towards patients carrying blood-borne viruses such as HIV infection, Hep.B and Hep.C and identifies perceived barriers from the dentists' perspective.

\section{DESIGN AND METHODOLOGY}

The study population was all dentists within the South Cheshire region. A list of all dentists practising in the region was obtained from the local Health Authority. The study design was a self-reported, written mailed questionnaire designed to assess the knowledge, attitudes, behaviour and to obtain socio-demographic information (see Appendix). The measures of knowledge, attitude and behaviour were modified from previous studies listed throughout this report, in order to attempt to collect consis- 
tent information and comparative data. This survey was pre-tested and developed at Manchester University Dental school. A cover letter, questionnaire and SAE was mailed to each dentist. The SPSS statistical package was used to analyse the data. Frequencies, means and chi-squared $\left(\chi^{2}\right)$, tests and bivariate analysis were performed.

\section{RESULTS}

Of the 330 mailed questionnaires, 152 were eventually returned. This was after having sent out a repeat questionnaire to nonrespondents 3 weeks after the first mailing. This gave a final response rate of $46 \%$. The majority of the respondents were general dental practitioners $(n=115,76 \%)$, with only 1 respondent working in a dental access centre, $20(13 \%)$ in the community dental service, $5(3 \%)$ in a hospital-based service and $9(6 \%)$ of the dentists working in more than one of these settings. Ninety (59\%) of the respondents were male and $40 \%$ were female. Ninety-three per cent $(n=141)$ described their ethnic group as White, 1 person as Black and 3 people as Asian. The age ranges of respondents is shown in Table 1. The mean number of years in dental practice was 17.5 , with the lowest being 1.5 years and the highest 38 years.

Table 1 Age range of dentists repsonding to
the survey
\begin{tabular}{lcc}
\hline & Frequency & $\%$ \\
\hline $20-30$ years & 25 & 16 \\
\hline $31-40$ years & 44 & 29 \\
\hline $41-50$ years & 51 & 34 \\
\hline $51-60$ years & 27 & 18 \\
\hline $60-70$ years & 2 & 1
\end{tabular}

For the purposes of SPSS analysis, some of the above data were recoded. For instance, in terms of dental practice, respondents were divided into two groups. These consisted of Group 1 (GDPs) and Group 2 (all dentists working in settings 'other' than general dental practice ie hospitals, CDS, access centres and those working in a mixture of settings). In terms of years in dental practice, respondents were divided into two groups: those in practice for less than 10 years, and those for more than 10 years. And finally, in terms of age, respondents were divided into 'younger' dentists (those below the age of 40) and 'older' dentists (those above the age of 40).

\section{KNOWLEDGE OF ORAL LESIONS}

Table 2 is a list of eight oral lesions associated with HIV/AIDS (derived from Quartey $\left.1998^{1}\right)$. The central column indicates the percentage of respondents correct knowledge, and the right hand column provides a comparison of such knowledge with results obtained in a previous study. Only 6\% of respondents correctly associated all eight lesions with HIV/AIDS (exactly the same percentage as in Quartey's (1998) previous study). However, the vast majority of respondents correctly associated all four lesions strongly associated with HIV infection (Group 1 lesions). The mean number of correct responses was $4.5(\mathrm{SD} \pm 1.7)$ which is similar to previous studies. ${ }^{1,5}$ No significant differences were found between knowledge scores and other variables such as gender, age, type of practice and years in dental practice.

\section{KNOWLEDGE OF MODES OF TRANSMISSION}

Table 3 assesses respondents knowledge of proven modes of transmission of HIV

Table 3 Respondents' knowledge of proven
modes of HIV transmission

infection. Ninety-nine per cent of respondents correctly identified blood as a mode of transmission of HIV. However, 46\% incorrectly cited saliva, even though there is no documented case to support this view. This result is similar to a national survey of dentists conducted in the USA which found $44 \%$ of dentists citing saliva as a vehicle for HIV transmission. ${ }^{1}$ Despite the fact that the World Health Organisation and UNICEF have recommended HIV infected women in developed countries not breast feed their babies to prevent perinatal transmission of the HIV virus, only $30 \%$ of respondents in this study know of the infectivity of breast milk. It was interesting to note that only $24 \%$ of GDPs were aware of breastmilk as a mode of transmission, in comparison with $51 \%$ of dentists working in 'other' settings $\left(\chi^{2}=10.7, \mathrm{df}=3, P<0.01\right)$.

The low percentage of correct responses to 'mucus' and 'tears' also suggests a considerable degree of uncertainty amongst this sample regarding knowledge of transmission for HIV infection. Apart from breastmilk, no significant differences were found between knowledge of modes of transmission and other variables such as gender, age, type of practice and years in dental practice.

\section{BEHAVIOURS}

Seventy dentists (46\%) were aware of ever having treated an AIDS or HIV+ patient. This compares with 31\% reported in a national survey in the USA. ${ }^{6}$ A number of interesting differences emerged in relation to this question. For instance, younger dentists (below the age of 40) were more likely to report having treated HIV/AIDS patients than older dentists (57\% compared with $\left.39 \%, \chi^{2}=6.3, \mathrm{df}=2, P<0.04\right)$. Also, dentists practising in the CDS or hospitals or access centres (categorised as 'other' dental settings), were more than twice as likely to report having treated HIV/AIDS patients than GDPs (77\% compared with $\left.37 \%, \chi^{2}=22.4, \mathrm{df}=2, P<0.0001\right)$.

Within the past 6 months, $77 \%$ of dentists reported not having treated any HIV+/ AIDS patients. Again, an interesting differ- 
Table 4 Percentage of respondents' attitudes towards treating various 'at risk' groups.

\begin{tabular}{lccc}
\hline $\begin{array}{l}\text { How would you feel } \\
\text { about treating: }\end{array}$ & 'No hesitation' & $\begin{array}{c}\text { 'Accept with some } \\
\text { hesitation' }\end{array}$ & $\begin{array}{c}\text { 'Refer patient } \\
\text { elsewhere' }\end{array}$ \\
\hline A homosexual/bisexual man & 87 & 11 & 2 \\
\hline A hemophiliac & 69 & 16 & 15 \\
\hline A patient infected with Hep.B virus & 48 & 43 & 9 \\
\hline An IV drug user & 52 & 35 & 21 \\
\hline A patient infected with Hep. C virus & 39 & 38 & 20 \\
\hline A patient diagnosed with HIV/AIDS & 45 & 35 & 1
\end{tabular}

Table 5 Significant differences between attitudes towards 'at risk' patients and age, dental practice and years in dental practice. Percentage of respondents who would be 'hesitant' in accepting patients and/or would refer.

\begin{tabular}{|c|c|c|c|}
\hline & Age & Years in practice & Type of practice \\
\hline & Younger Older & Lower Higher & GDP Other \\
\hline \multicolumn{4}{|l|}{ 'Atrisk'group } \\
\hline Homosexual/ bisexual & $6 \% \vee 17 \% *$ & $3 \% \vee 14 \%$ & $16 \% \vee 3 \% *$ \\
\hline Hep.B & 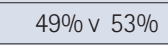 & $38 \%$ v $55 \%$ & $59 \% \vee 29 \%{ }^{+}$ \\
\hline Drug user & $44 \% \vee 50 \%$ & $29 \% \vee 53 \% *$ & $56 \% \vee 23 \%{ }^{\dagger}$ \\
\hline Hep.C & $59 \% \vee 62 \%$ & $44 \%$ v $66 \%{ }^{*}$ & $70 \% \vee 31 \%{ }^{+}$ \\
\hline HIV/AIDS & 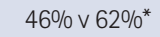 & $38 \% \vee 59 \%{ }^{*}$ & $65 \% \vee 26 \%{ }^{+}$ \\
\hline
\end{tabular}

* Statistically significant difference at the 0.05 level (2-tailed)

t Statistically significant difference at the 0.01 level (2-tailed) ence emerged regarding the type of dental practice. For instance, dentists working in 'other' settings were far more likely to report having treated HIV/AIDS patients than GDPs (49\% compared with 13\%, $\left.\chi^{2}=21, \mathrm{df}=1, P<0.0001\right)$.

\section{ATTITUDES}

\section{Attitudes towards 'at risk' groups}

Respondents' attitudes towards treating various groups considered to be at risk are shown in Table 4. As can be seen, a relatively large proportion of dentists remain uncertain about treating patients in some of these categories. For instance, only $45 \%$ of respondents would accept a HIV/AIDS patient with 'no hesitation'. But this uncertainty was not confined to HIV/AIDS patients - comparable figures can be seen in relation to patients infected with Hep. B (only 48\% of dentists would accept with 'no hesitation'), the Hep. C virus (39\%) and IV drug users (52\%). On the basis of these results, the hesitation regarding HIV/AIDS patients does not seem to extend to homosexual/bisexual patients $(87 \%$ of dentists said they would have no hesitation accepting such patients).

Some very interesting differences were revealed in terms of attitudes towards 'at risk' patients and differences in age, type of dental practice, and years in dental practice. These are summarised in Table 5.

\section{Attitudes towards 'risk' of infection}

In general, again consistent with previous studies, ${ }^{1}$ respondents indicated a slight to moderate concern with regard to occupational exposure to HIV. Fifty-five per cent of respondents agreed that they had an increased risk for HIV due to occupational exposure. However, only $3 \%$ of respondents believed HIV transmission in dental clinics was 'very likely' (compared with 19\% in Quartey's (1998) study), and only 34\% agreed that they were 'worried' about occupational exposure to HIV infection. A large majority of dentists (91\%) believed that the infection control procedures in their place of work were adequate to prevent cross infections. Unlike previous studies ${ }^{1,7}$ which found higher perceptions of occupational risk to HIV exposure amongst female dentists, no significant gender differences were found in this sample.

In terms of actual use of infection control barriers: $97 \%$ of dentists reported that they wore gloves routinely (this compares to $88 \%$ in a survey of dentists in England during $1991-2) ; 866 \%$ used a face mask routinely (21\% 'sometimes' and 12\% 'rarely'); and $86 \%$ used protective eye glasses routinely (11\% 'sometimes' and 3\% 'rarely'). There were no significant differences between use of infection control procedures and factors such as gender, age, type of dental practice or years in practice.

When it was suggested that additional resources be made available to treat HIV infected patients, 54\% of respondents agreed, while 22\% disagreed (the rest were 'undecided'). Interestingly, when compared with dentists working in 'other' settings, GDPs were almost twice as likely to agree that additional resources should be made available to treat HIV infected patients (61\% compared with $37 \%, \chi^{2}=7.4, \mathrm{df}=2$, $P<0.02)$.

\section{ETHICAL ISSUES}

Sixty-six per cent of respondents agreed with the statement 'As a dentist, I have an ethical responsibility to provide dental care regarding acceptance of homosexual/ bisexual patients and HIV/AIDS patients, when compared with younger dentists.
Table 6 Correlations (Pearson's $r$ ) between 'ethical responsibility' and attitudes towards 'at risk' patients

\begin{tabular}{ll}
\hline How would you feel about treating: & $\begin{array}{l}\text { 'As a dentist, I have an ethical responsibility } \\
\text { to provide dental care to a HIV positive person' }\end{array}$
\end{tabular}

A homosexual/ bisexual man $0.29^{\dagger}$

A hemophiliac 0.19

A patient infected with Hep.B virus $0.34^{\dagger}$

\begin{tabular}{ll}
\hline An IV drug user & $0.30^{\dagger}$
\end{tabular}

A patient infected with Hep. C virus $\quad 0.27^{\dagger}$

A patient diagnosed with HIV/AIDS $0.45^{+}$

A recipient of blood and blood products $0.34^{\dagger}$

${ }^{*}$ Correlation is significant at the 0.05 level (2-tailed)

${ }^{+}$Correlation is significant at the 0.01 level (2-tailed) 


\begin{tabular}{|c|c|c|}
\hline Potential concerns: & $\begin{array}{c}\text { Percentage } \\
\text { 'concerned' (\%) }\end{array}$ & $\begin{array}{l}\text { Compared with previous } \\
\text { McCarthy et al. }{ }^{5} \text { study }(\%)\end{array}$ \\
\hline 1. Loss of other patients from practice & 34 & 68 \\
\hline $\begin{array}{l}\text { 2. Dealing with staff fears about patients } \\
\text { with HIVIAIDS }\end{array}$ & 59 & 67 \\
\hline $\begin{array}{l}\text { 3. Increase in personal risk due to } \\
\text { treating patients with HIVIAIDS }\end{array}$ & 36 & 63 \\
\hline $\begin{array}{l}\text { 4. Financial burden for the practice due to } \\
\text { increased infection control procedures }\end{array}$ & 32 & 45 \\
\hline
\end{tabular}

to a HIV+ person'. Nineteen per cent disagreed and 15\% remained undecided. Again, some interesting differences emerged in relation to years in dental practice, age of dentists, and type of dental practice. For instance, dentists who had been in practice for less than 10 years were significantly more likely to agree with this statement than dentists who had been practising for more than 10 years (91\% compared with $60 \%, \chi^{2}=12.7$, df $=2$, $P<0.002$ ). Likewise, $82 \%$ of younger dentists agreed with the statement in comparison with only 53\% of older dentists $\left(\chi^{2}=14.9\right.$, df $\left.=2, P<0.001\right)$. And finally, $91 \%$ of dentists in 'other' types of dental practice agreed in comparison with only $58 \%$ of GDPs ( $\chi^{2}=13$, df $\left.=2, P<0.001\right)$.

Previous studies have shown that a sense of ethical responsibility is important because it is one of the strongest predictors of refusal or unwillingness to treat HIV/ AIDS patients. $^{9}$ For instance, in the McCarthy et al. (1999) study, it was found that respondents who did not have a sense of ethical responsibility were nine times more likely to report that they would refuse to treat HIV infected patients than respondents who believed they did have such an ethical responsibility. In this respect, it is interesting to note the significant correlations which exist in the current investigation between the statement 'As a dentist, I have an ethical responsibility to provide dental care to a HIV positive person' and the variables addressing attitudes towards various 'at risk' patients (see Table 6).

Another statement in the survey was also designed to assess respondents' sense of ethical responsibility: 'Health professionals should have the right to refuse to provide treatment for a HIV+ person'. A minority of $36 \%$ agreed with this statement, with 44\% disagreeing, and 20\% being undecided. Again, similar differences in age and years in dental practice were manifest. For instance, 61\% of dentists practising for under 10 years disagreed with it, in comparison with 39\% practising for over 10 years $\left(\chi^{2}=10\right.$, $\mathrm{df}=2, \quad P<0.006)$. Likewise, $53 \%$ of younger dentists disagreed, in comparison with $36 \%$ of older dentists $\left(\chi^{2}=6.1\right.$, $\mathrm{df}=2, P<0.05)$. Gender differences were also apparent in relation to this question; women twice as likely to disagree than men $\left(63 \%\right.$ compared with $31 \%,\left(\chi^{2}=14.7\right.$, df $=2, P<0.001)$.

\section{CORRELATIONS BETWEEN KNOWLEDGE AND ATTITUDES}

Previous studies have suggested that knowledge may affect attitudes towards treatment of HIV/AIDS patients. ${ }^{1,9}$ This was borne out in the current study where significant differences were found between those obtaining higher compared with lower oral knowledge scores and willingness to treat various 'at risk' patient groups. For instance, those with higher scores were significantly more likely than lower scorers to respond that they would 'have no hesitation' in treating the following patients groups: a homosexual/bisexual man (96\% compared with $78 \%, \chi^{2}=11, \mathrm{df}=2$, $P<0.001)$; a hemophiliac $(77 \%$ compared with 58\%, $\chi^{2}=6$, df $\left.=2, P<0.05\right)$; and a HIV/AIDS patient (55\% compared with $35 \%, \chi^{2}=6$, df $\left.=2, P<0.05\right)$. In addition, those with higher oral knowledge scores manifested a greater sense of ethical responsibility compared with lower scorers. For instance, higher scorers were significantly more likely to agree that a dentist has an ethical duty to treat HIV+ patients (80\% compared with 53\%, $\chi^{2}=19$, df $=2$, $P<0.0001)$. Conversely, significantly less of the higher scorers believed health professionals had the right to refuse treatment to a HIV+ person than lower scorers $(42 \%$ compared with $30 \%, \chi^{2}=7, \quad \mathrm{df}=2$, $P<0.05)$

\section{PERCEIVED BARRIERS TO ACCEPTING HIV/AIDS PATIENTS}

Respondents were asked about a number of potential concerns relating to the treatment of HIV/AIDS patients which have been reported in previous studies. ${ }^{9}$ These included: 1) Loss of other patients from the practice; 2)Dealing with staff fears about patients with HIV/AIDS; 3) Increase in personal risk due to treating patients with HIV/ AIDS; and 4)Financial burden for the prac- tice due to increased infection control procedures. Table 7 documents responses to these questions. As can be seen, the greatest fear of respondents related to dealing with staff fears, with 59\% of respondents expressing concern. As is also shown, however, concern in relation to all of these issues was considerably lower than a previous study based on Canadian dentists.

Once again, significant differences were found between these concerns and type of dental setting. GDPs were significantly less likely than 'other' dentists to report feeling 'not at all concerned' about: potential loss of patients (38\% compared with 87\%, $\left(\chi^{2}=22, \quad \mathrm{df}=1, \quad P<0.0001\right) ;$ staff fears (23\% compared with 53\%\%, $\chi^{2}=11$, df $=1, P<0.001)$; and finally, financial burden (42\% compared with $83 \%, \chi^{2}=16$, df $=1, P<0.0001)$.

\section{CONCLUSION}

The results of this study suggest that age and type of dental practice are significant factors associated with actual self-reported treatment behaviour (ie whether the dentist has ever treated a HIV/AIDS patient) amongst dentists practising in the South Cheshire region (nb there was no significant correlation between age and type of dental practice, hence no confounding of variables). In particular, younger dentists and dentists working in settings 'other' than the GDP environment, were more likely to report having treated HIV/AIDS patients.

Likewise with regard to attitudes towards various categories of 'at risk' patients. GDPs were more hesitant regarding their willingness to accept all categories of 'at risk' patients than 'other' dentists. In addition, older dentists and dentists who had been in practice for more than 10 years, expressed greater reservations with regard to 'at risk' patients than did younger dentists and those who had been in practice for less than 10 years. It is important to note that the results of this study are consistent with those obtained in previous research, in which it was found that hesitance in treating HIV/AIDS patients was not confined to this group, but also extended to other groups at high risk of blood-borne pathogens. ${ }^{9}$

A similar pattern also held in relation to questions assessing a sense of ethical responsibility. Younger dentists and those who had been in practice for less than 10 years, along with dentists practising in 'other' settings, showed more of a sense of ethical responsibility than their comparison groups. These findings are also consistent with previous research which found that younger dentists were least likely to refuse treatment of HIV infected patients and were also more likely to report a sense of ethical responsibility towards providing such treatment. ${ }^{9-11}$ 
One previous interpretation of the effect of age on treatment behaviour and attitudes towards 'at risk' patients, suggested that the degree of 'avoidance behaviour' increases with the number of years since graduation from dental school. ${ }^{12}$ Possibly a more convincing interpretation, however, is the impact of educational programmes on willingness to treat HIV positive patients. ${ }^{13}$ McCarthy et al. ${ }^{9}$ suggest that younger dentists may have received more formal training related to HIV than older dentists. A previous study in England and Wales has also found a significant association between willingness to treat HIV/ AIDS patients and attendance at postgraduate courses. ${ }^{14}$ This may also account for why dentists in 'other' settings report greater willingness to treat 'at risk' patients than GDPs - possibly they are more exposed to continuing educational programmes? McCarthy et al. argue that appropriate emphasis on ethics training at the undergraduate, postgraduate and in continuing education may improve healthcare workers' sense of ethical responsibility and lead to a greater willingness to treat patients with bloodborne pathogens. Such education may also serve to address the concerns, specifically of GDPs, relating to treatment of HIV/AIDS patients. In this study, such concerns related to potential loss of patients, dealing with staff fears, and additional financial burdens imposed on the practice. On the other hand, it is valid to ask to what extent continuing education could actually do anything to address these problems. It may be that the concerns of GDPs represent real problems (ie that accepting HIV/AIDS patients would result in loss of other patients, increased staff problems and incur further financial costs). If this is the case, something more than education is needed to address such problems. It is recommended that further qualitative research be conducted in order to investigate these issues in more detail.

One final point should be made regarding the response rate in this study. All of the normal procedures for obtaining as high a response rate as possible were followed in this study. ${ }^{15}$ What is presented is simply an honest representation of the responses returned. There has been no attempt to artificially inflate the response rate in the manner that so much contemporary research is covertly encouraged to do. When compared with 'traditional' medical research which often uses 'captive' populations such as patients, the response rate of $46 \%$ may appear quite low. However, such a response rate is certainly not untypical of a great deal of contemporary 'real world' social research in which researchers are faced with the difficulty of getting people to respond to questionnaires in a climate where they are increasingly inundated with information and requests for information. As any such researcher is fully aware, people (including health professionals!) are becoming increasingly reluctant and 'resistant' to participating in research and filling in questionnaires. ${ }^{16}$ It is also important to consider that this research addressed quite 'sensitive' topics such as HIV/AIDS and its 'moral' connection to issues of sexuality. Research on such issues is notorious for its inability to achieve the same response rates as with more 'morally neutral' issues.

Having said that, it is, of course, as with any research, important to be cautious in interpreting the results presented in this paper as representative of the views of dentists within the region. It may be the case, for instance, as one reviewer pointed out, that the dentists who were willing to give their names and addresses to be conducted to take part in a further interview, were quantitatively and qualitatively different to those who remained anonymous. Having said that, there were no significant differences between these two groups on the major socio-demographic variables measured in this study. There is, of course, no way of knowing if the characteristics of the non-responders were different to those of responders, because the information on the former remains unknown. In conclusion, the data presented in this study is of interest for the light it sheds on the knowledge, attitudes and beliefs of an (admittedly select) group of dentists working in a particular region. It is the task of further research to investigate the extent to which such beliefs are further generalisable within the dental profession.

1. Quartey J. Impact of HIV on the practice of dentistry in Houston, Texas. Texas Dent J 1998; November issue, pp45-57.

2. McCarthy M, Koval J, MacDonald J. Factors associated with refusal to treat HIV infected patients: The results of a national survey of dentists in Canada. Am J Public Health 1999; 89: 541-545.

3. Craven R, O'Brien K, Bennett E. Impact on English dentists of the threat of HIV infection. Community Dent Oral Epidimiol 1996; 24: 228-229.

4. Kunzel C, Sadowsky D. Comparing dentists' attitudes and knowledge concerning AIDS: differences and similarities by locale. J Am Dent Assoc 1991; 122: 55-61.

5. Gerbert B. The impact of AIDS and dental practice: Update 1989. J Dent Educ 1991; 53: 529-530.

6. Kunzel C, Sadowsky D. Comparing dentists' attitudes and knowledge concerning AIDS: differences and similarities by locale. J Am Dent Assoc 1991; 122: 55-61.

7. Kunzel C, Sadowsky D. Assessing HIV related attitudes and orientations of male and female dentists. J Am Dent Assoc 1995; 126: 862-870.

8. Burke F, Wilson N, Cheung S. Trends in glove use by dentists in England and Wales:1989-1992. Int Dent J 1994; 44: 195-291.

9. McCarthy M, Koval J, MacDonald J. Factors associated with refusal to treat HIV infected patients: The results of a national survey of dentists in Canada. Am J Public Health 1999; 89: 541-545.

10. Watt $R$, Croucher R. Dentists perceptions of HIV/AIDS as an occupational hazard: a qualitative investigation. Int Dent J 1991; 41: 259-264.

11. Sadowsky D, Kunzel C. Are you willing to treat AIDS patients? J Am Dent Assoc 1991; 122: 29-32.

12. Dove $S$, Cottone J. Knowledge and attitudes of Texas dentists concerning AIDS. Am J Dent 1990; 3: 5-8.

13. Gerbert B, McGuire B, Bader V et al.Changing dentists' knowledge, attitudes and behaviours relating to AIDS: a controlled educational intervention. J Am DentAssoc 1988; 166: 851-854.

14. Wilson N, Burke T, Cheung S. Factors associated with dentists' willingness to treat high-risk patients. BrDent J 1995: 178: 145-148.

15. de Vaus D. Surveys in Social Research. UCL Press: London, 1996.

16. Crossley M. The Health Resistance scale: Developing a measure of resistance to health promotion. Health Educ J 2002d; 60: 313-326. 


\section{Appendix 1 Questionnaire sent to dentists}

1) What type of dental practice are you involved in?

$\square$ Community Dental Service $\square$ Access centre $\square$ General dental practice

2) Please tick which of the following oral lesions you would associate with the manifestation of HIV/AIDS (please tick as many as necessary):

$\square$ Kaposi's Sarcoma $\square$ Oral candidiasis $\square$ Acute ulcerative gingivitis

$\square$ Hairy leukoplakia $\square$ Herpetic infections $\square$ Xerostomia

$\square$ Aphthous ulceration $\square$ Lichen planus/lichenoid reaction

3) Have the following body fluids have been proven as modes of transmission of HIV infection?

$\begin{array}{lccc} & \text { Yes } & \text { No } & \text { Don't know } \\ \text { Blood } & \square & \square & \square \\ \text { Saliva } & \square & \square & \square \\ \text { Breastmilk } & \square & \square & \square \\ \text { Vaginal secretions } & \square & \square & \square \\ \text { Semen } & \square & \square & \square \\ \text { Mucus } & \square & \square & \square \\ \text { Tears } & \square \\ & \square & \square & \square\end{array}$

4) The Hepatitis $B$ virus is more infectious and a greater hazard to nonvaccinated persons than HIV:

True $\square$ False $\square$ Don't know $\square$

5) To your knowledge, have you ever treated a HIV positive or AIDS patient?

Yes $\square$ No $\square$

6) To your knowledge, how many HIV positive/AIDS patients have you treated within the past 6 months:

$\begin{array}{cc}\square & 6 \text { or more } \\ \square & 3-5 \\ \square & 1-2 \\ \square & \text { None }\end{array}$

7) Please tick which of the following applies to your personal use of infection control procedures:

\section{I wear gloves}

I wear a face-mask

Routinely Sometimes Rarely

$\square \quad \square \quad \square$

I wear protective eye-glasses

$\square$

8) Please indicate the response which best describes your opinion in relation to the following statements:

Agree Disagree Undecided

The protection of dental workers from

occupational exposure to HIV is a high priority

for me

I am worried about occupational exposure to HIV infection

As a dentist, I am at increased risk of HIV infection

HIV transmission in dental clinics is very likely

The infection control measures in my place of work are adequate to prevent cross infection of HIV

Additional resources should be made available to treat HIV infected patients

As a dentist, I have an ethical responsibility to provide dental care to a HIV positive person
Health professionals should have the right to refuse to provide treatment for a HIV infected person

9) How would you feel about treating the following patients?

I would have I would accept I would refer no hesitation the patient with the patient some hesitation elsewhere

A homosexual/bisexual man

$\begin{array}{ll}\square & \square \\ \square & \square \\ \square & \square\end{array}$

An IV drug user

$\square$

$\square$

A patient infected with Hep. B virus

A patient infected with Hep. C virus

$\square \quad \square$

$\square$

A patient infected with a

HIV/ AIDS diagnosis

$\square$

$\square$

$\square$

A recipient of blood and blood products

10) In treating a HIV/ AIDS patient, how concerned would you be about the following:

Concerned Notatall Undecided concerned

Loss of other patients from

the practice

Dealing with staff fears about patients with HIV/ AIDS

Increase in personal risk due to treating patients with HIV

Financial burden for the practice

due to increased infection control procedures

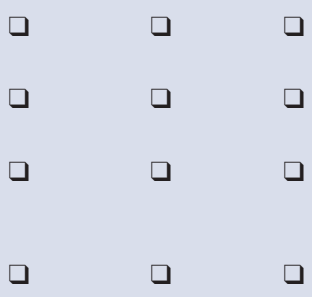

Please could you supply some details about yourself:

1) I am:

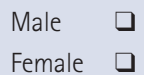

2) I am years of age

3) I have been in dental practice for years

4) Do you provide NHS dental services? Yes $\square$ No $\square$

5) How would you describe your ethnic group? (eg White, Black, Asian)

We would like to thank you for taking the time to fill out this questionniare. If you would be willing to participate in a short interview to discuss some of these issues further (either telephone, face to face or by email), please could your name and a contact address and telephone number/email address in the space provided below: Name

Contact telephone/ email address

Address: 